\title{
Thai Early Childhood Education Quality Assurance Assessor Competency Development Analysis
}

\author{
Khanidtha Tangwarasittichai, King Mongkut's Institute of Technology Ladkrabang (KMITL), Thailand, \\ n.nid_2550@hotmail.com, ORCID:0000-0002-4685-2925 \\ Punnee Leekitchwatana, King Mongkut's Institute of Technology Ladkrabang (KMITL), Thailand, \\ punnee.le@kmitl.ac.th,ORCID:0000-0002-1355-2811 \\ Paitoon Pimdee, King Mongkut's Institute of Technology Ladkrabang (KMITL), Thailand, \\ paitoon.pi@kmitl.ac.th, ORCID:0000-0002-3724-2885
}

\begin{abstract}
In Thailand, starting in 2000, education quality assessment was tasked to the Office for National Education Standards and Quality Assessment (ONESQA). Subsequently, 5-year cycles (rounds) were established to assess Thai educational institutions. In Round 1, 35,134 schools at the basic education level were assessed. Subsequently, numerous issues concerning the external assessors' (EA) competency were raised. Therefore we undertook a 2nd-order confirmatory factor analysis (CFA) of the study's three latent and 17 observed variables concerning early childhood education EA competency. Multi-stage random sampling was used to conduct the sample survey of 400 early childhood education quality assurance (QA) EAs across 40 Thai provinces covering four regions. IBM's $®$ SPSS $®$ Amos ${ }^{\mathrm{TM}} 24$ software was used for the analysis. Results revealed that EAs perceived their information technology skills (SH) as critical. This was followed by early childhood education knowledge (KA) and true friends (AA).

Keywords: Competency, Early childhood, Elementary education, Education evaluation, ONESQA, Quality assurance

$\begin{array}{lll}\text { Received: } 13.11 .2020 & \text { Accepted: 06.12.2020 } & \text { Published: 07.01.2021 }\end{array}$
\end{abstract}

\section{INTRODUCTION}

Numerous scholars have expressed their opinions concerning which characteristics one should find in early childhood programs (Hussain \& Juma, 2006), with some believing that social and cultural contexts play key roles, as well as the services which are provided. However, what constitutes quality in one setting may be different in another setting. However, educational assessment is a process of determining how well students are learning and is an integral component in the quest for improving education (NRC, 2001). This is also consistent with Tantimedh et al. (2013), who indicated that competencies within different contexts may require the use of various groups of skills, attitudes, and knowledge.

In the European Union's candidate country of Montenegro, early childhood education QA is accomplished both internally and externally (European Commission, 2019), with external assessments scheduled once every four years. However, the focus of the assessment is on student knowledge assessment and achievements.

Also, within the EU, Hungary's educational QA process involves a self-evaluation, an external pedagogical-professional inspection, and student standardized testing (European Commission, 2020). Hungary has also established a unified computer network and database for professionals involved in early childhood interventions to monitor the child's way of living and to strengthen parents' cooperation with the children's guardians. This is consistent with Arikan et al. (2017) which discussed the benefits and importance of early childhood educators acquiring information technology proficiency. Hungary, like Thailand, also has a five-year external evaluation cycle, which has primary responsibility for the inspection of educators, school heads, and the institutions themselves. Online anonymous questionnaires are also used in the evaluation process.

Like Hungary, Turkey also maintains a database of QA input, with each QA team tasked to undertake an external evaluation subject to a regular review (European Commission, 2019). Regarding Turkish early childhood education and care (ECEC), Gol-Guven (2020) has added that expert consensus indicates that early childhood education pays off, which is significantly supported by other global research. Therefore, quality also has to be recognized as one of the strongest elements of Turkey's ECEC services. 
In Thailand, starting in November 2000, the process of education quality assurance (QA) and a defined set of educational standards assessment was formalized under the Office for National Education Standards and Quality Assessment (ONESQA) (Pitiyanuwat, 2007). The National Education Act of 1999 (2nd Amendment in 2002) required all education institutions to establish internal QA systems (Office of the Higher Education Commission, 2014). Therefore, ONESQA was established to certify educational standards and assess each institution's quality.

Serving as an independent public organization that is autonomous from the bureaucratic and financial lines of command (ONESQA, 2017), ONESQA today has undertaken four rounds of assessment taking place from 2001 - 2020. During each five-year cycle, every Thai school is assessed, which in Round 1 included 35,134 schools at the basic education level. By 2015, ONESQA stated that its mission included 38,010 educational institutions, 660,000 teachers/lecturers, and over 13 million students ('ONESQA says its evaluation takes 5 hours', 2015).

Over the years assessment objectives and goals have shifted in Thailand, with more recent assessments underpinning principles concerning cleanliness, hygiene, and beauty (campus and environment enhancements) (ONESQA, 2015). Moreover, according to ONESQA, these three principals are applied to all schools, with emphases on classrooms, toilets, and dining halls, which are stated to be at the heart of each school's site inspection today. These objectives are also consistent with ECEC services as stated by the OECD (2017), in which it was stated that in addition to education investment and quality teachers, the school's environment was essential. Additionally, the school's curriculum framework can play a key role as well.

Furthermore, in 2015 after the identification of the weakness in external assessor (EA) qualifications in early childhood education, further measures were undertaken to raise the standard within the EA ranks (Pornrungroj, 2015). To achieve this, a program entitled QC 100 was defined and undertaken as a means of assuring the quality of all EAs at all levels. Assessor QA is now reviewed by a method in which ONESQA sends out questionnaires to each institution asking for feedback and recommendations for assessor improvement. Also, the QC 100 assessor monitoring system is used "to sanction or reinforce the morale of those who perform their duties with integrity" (Pornrungroj, 2015, p. 7).

Moreover, Chantana et al. (2019) identified three core competencies needed for Thai higher education EAs. These included knowledge and understanding, ability and skills, and attributes. This is consistent with the OECD, which has also pointed out a key challenge in providing quality services for children are knowledge gaps, curriculum, parents, financing, the teaching workforce, equity in access, and government (OECD, 2017).

Furthermore, Suchiva et al. (2018) also investigated Thai EA competencies and examined ongoing processes during the most recent evaluation and assessment cycle (Round 4). From the results of the research, some Round 4 EAs were determined to not comply with information technology (IT) use infield record keeping due to lack of IT skills. Moreover, EA's recommendations were not consistent with the established standards used in Thai ministerial regulations. Also, child development centers and early childhood education in schools are somewhat different, with some EAs lacking the ability to understand the nature of both educational arrangements. Other issues identified were the lack of educational management skills, as well as ongoing concerns about the ethics of the EAs.

Finally, in the 20-year evolution of QA assessment, assessors have moved from being labeled 'true friends' to 'Ambassadors of Quality' (ONESQA, 2015; Pornrungroj, 2011). Figure 1 details the values, ethics, and characteristics each QA assessor is stated by ONESQA to strive for. 


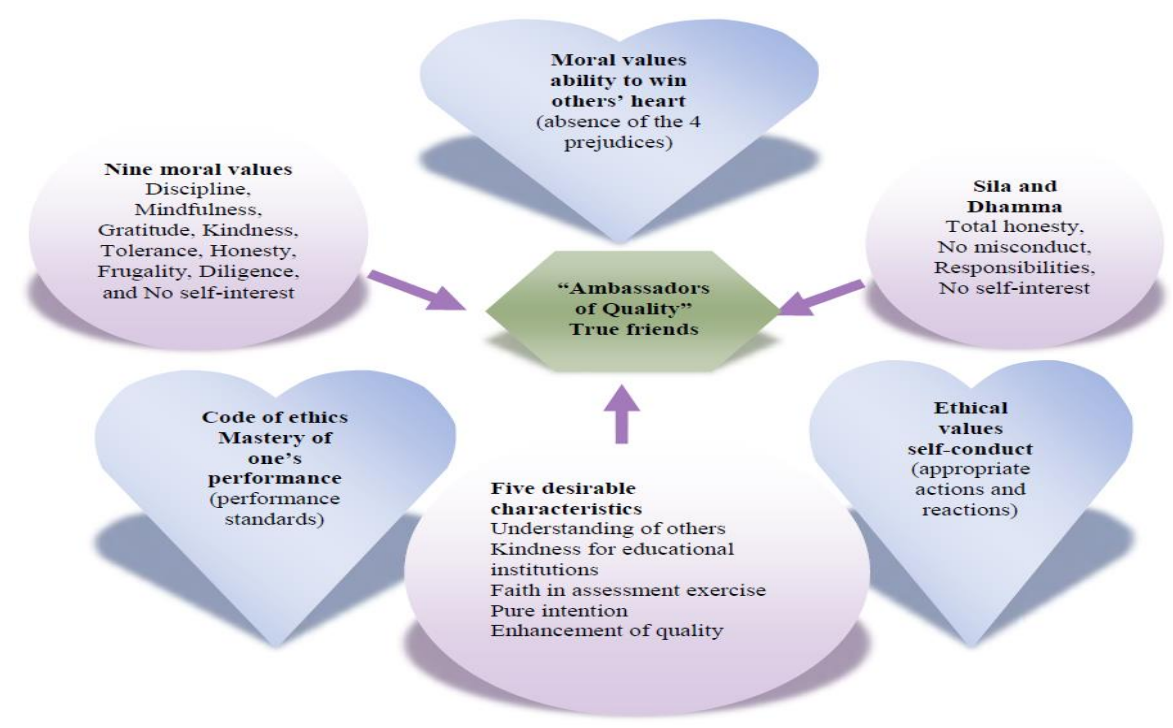

Figure 1. Thailand's concept of early childhood education assessor as 'Ambassadors of Quality'. Source: (Pornrungroj, 2011)

Therefore, we are interested in studying the composition of external education assessors within the Thai early childhood education process. From a review of associated literature and theory, we have identified three latent variables along with their associated 17 observed variables related to an external QA assessor's competency (Table 3).

\section{RESEARCH OBJECTIVES}

1. To study the composition and indicators of external assessors of early childhood education.

2. To determine the competency of external assessors

3. To develop methods and a model in assessing the competency of early childhood education external QA assessors.

\section{METHODS}

\section{Population and Sampling Techniques}

We determined at the time of the study in 2019 the population of professionals working within ONESQA as education assessors totaled 668 individuals. From the theory related to sample sizes, a sample of 400 was determined as meeting the criteria determined by various scholars and numerous studies (PImdee, 2020). Moreover, Ross (2005) has suggested that UNESCO educational research should use a sample size of 400 in studies using simple random sampling techniques, as 400 assures a $95 \%$ confidence limit of $\mathrm{p} \pm$ $5 \%$.

Furthermore, multistage random sampling was selected as it is a process that takes a series of simple random samples in stages and is useful where a survey is conducted from multiple locations (Kanyacome et al., 2012). Furthermore, for this study multistage random sample was useful as the target area was large (provinces within Thailand), which also allowed for the division of the survey teams into four regional areas (stratified random sampling) consisting of 10 provinces each. Thereafter, simple random sampling was employed to select each targeted individual, whereupon, the researcher collected the data by questionnaires on external assessor competence in early childhood education who attended four separate Early Childhood Education Competency Development Conferences organized by ONESQA during December 2019 to January 2020.

\section{Research Tools}

During the first phase of the research, we analyzed both theory and the literature related to indicators used in the evaluation of quality assurance EAs involved in early childhood education. This included information on EA qualifications, their roles, their code of conduct and ethics, training courses, information technology use, and qualifications. In addition, we also studied the empirical data by attending and observing the training of Thai external QA assessors organized by ONESQA. Interviews were also conducted with stakeholders, trainers, school administrators, and the EAs themselves who had 
been certified by the Association of External QA assessors. These interviews were directed at three main points including:

1) Competency components of external QA assessors.

2) External assessors' performance indicators.

3) The weight, value, and significance of the indicator elements.

\section{Development of the Questionnaire}

Questionnaire consistency and validity were assessed before the main survey. This was accomplished with five experts assembled by the researchers whose task was to evaluate our questionnaire. One common method used in the assessment process is the indexes of item-objective congruence (IOC). Turner and Carlson (2003) have suggested IOC values $\geq 0.50$ are adequate for item reliability. From the study, the IOC values were 0.8 - 1.00 which met and exceeded established criteria for item validity.

Thereafter, a pre-survey pilot-test of 30 individuals was conducted whose questionnaires were not used in the subsequent sample. Assessment of the pilot-test reliability was accomplished with the use of Cronbach's $\alpha$ (George \& Mallery, 2010). From this, average $\alpha$ was established at 0.92, exceeding the recommended value of $\geq 0.70$.

\section{Data Collection}

We collected questionnaires from 400 individuals concerning their opinions on the competency indicators identified for external quality assurance early childhood assessors from December 2019 to January 2020. A total of 400 questionnaires were received, representing 100\%.

The questionnaire was organized into two parts. Part 1 consisted of each assessor's general information which included their gender, age, years of experience, and how many Rounds of assessment they have participated in.

Part 2 used a five-level agreement scale to rank the opinions of each assessor. Strongly agree was indicated by a ' 5 ' whose value was 4.50 - 5.00, agree was indicated by a ' 4 ' whose value was $3.50-4.49$, uncertain was indicated by a ' 3 ' whose value was $2.50-3.49$, disagree was indicated by a ' 2 ' whose value was $1.50-2.49$, and strongly disagree was indicated by a ' 1 ' whose value was $1.00-1.49$. Moreover, Part 2 was divided into three sections, which contained the three latent variables and the 17 observed variables.

\section{RESULTS}

\section{External Assessor Personal Characteristics}

The majority of the early education assessors were female (69\%), with 94\% having a Master's degree, while the remaining 6\% held a Ph.D. (Table 1). Also, 51.5\% were from 46 - 55, while $25.25 \%$ were between 35 - 45 years of age, with the remaining 23.25\%, 56 years or older. Further responses indicated that $35.75 \%$ of the assessors had completed Round 1's assessment of 35,134 Thai schools (Pitiyanuwat, 2007), while $65.25 \%$ had participated in one of the subsequent 5-year evaluation cycles (ONESQA, 2017).

Table 1. Assessors' personal and professional characteristics $(n=400)$

\begin{tabular}{|l|c|c|}
\hline \multicolumn{1}{|c|}{ Characteristics } & Assessors (n) & Percentage (\%) \\
\hline Gender & & \\
\hline Male & 124 & 31.00 \\
\hline Female & 276 & 69.00 \\
\hline Education level & 378 & 94.00 \\
\hline Master's degree & 22 & 6.00 \\
\hline PhD & & \\
\hline Age (years) & 101 & 25.25 \\
\hline Between 35-45 & 206 & 51.50 \\
\hline Between 46-55 & 93 & 23.25 \\
\hline 56 years and over & & \\
\hline $\begin{array}{l}\text { External quality assessment } \\
\text { experience (years) }\end{array}$ & 143 & 35.75 \\
\hline Round 1 (2001 - 2005) & 257 & 65.25 \\
\hline Rounds 2 - 4 (2006 - 2020) & & \\
\hline
\end{tabular}




\section{Goodness-Of-Fit (GOF) Appraisal}

Numerous scholars have discussed and recommended the use of convergent validity (CV) as a method to assure the expected variable relationship validity. As such, CV is determined by the use of the GFI $(\geq 0.95)$, the CFI $(\geq 0.90)$, the RMSEA $(\leq 0.05)$, and the chi-square/df statistic $(\leq 2.00)$ (Bollen, 1989; Diamantopoulos \& Siguaw, 2000; Fan \& SIvo, 2005; Schumacker \& Lomax, 2010). The relative Chi-square $(\mathrm{x} 2 / \mathrm{df})$ is also suggested as $\leq 2.00$ (Pimdee, 2020). Therefore, from the study's AMOS 24 GOF analysis, the Chi-Square $=92.87, \mathrm{df}=80, \mathrm{p}=0.15, \chi^{2} / \mathrm{df}=1.16, \mathrm{RMR}=0.01, \mathrm{SRMR}=0.01, \mathrm{RMSEA}=0.01, \mathrm{GFI}=0.98$, and AGIF $=0.98$. From these criteria, the final model was determined to fit well with the data (Arbuckle, 2016).

\section{Descriptive Analysis}

Details in Table 2 present the results from the descriptive analysis of each observed variable using the mean $(\bar{x})$, standard deviation (S.D.), skewness, and the kurtosis, with the p-values of the skewness and kurtosis used to assess the normality of the data (Kim, 2015). Furthermore, Curran et al., (1996) has suggested as values for skewness approach 2.00 and values for kurtosis approach 7.0, values become suspect. Hair et al. (2010) have suggested an even lower threshold for skewness, suggesting a value of less than 1.00 .

Therefore, an analysis of the study's 17 observed variables revealed that an assessor's ability to summarize their findings (SC) was strongly agreed with $(\bar{x}=4.86)$. Other skills closely followed, which included their data collection (SB) skills and their planning ability (SA) skills $(\bar{x}=4.75)$. Under knowledge $(\mathrm{K})$, the assessor's educational institution context knowledge (KB) was viewed most important $(\overline{\mathrm{x}}=4.51)$, while under aspects $(\mathrm{A})$, true friends $(\mathrm{AA})$, was perceived as most important $(\overline{\mathrm{x}}=$ 4.77).

ONESQA's past references as EAs as true friends (Rounds 1 - 2), was changed to Ambassadors of Quality starting in Round 3 (ONESQA, 2015), whose tasks are to provide advice and recommendations for an educational institution's quality improvement. Moreover, school assessments are supposed to be amicable, with EAs also being referred to as 'school doctors' in the earlier rounds of external quality assessment. Also, starting in Round 3, the EA Ambassadors of Quality assumed more extensive roles, with the ultimate objective stated to be the improvement of educational institution quality to sustainably attune to the change in all dimensions. Furthermore, ONESQA (2015) stated that the quality development of Thai early learners was the ultimate goal, thus allowing them to become a competent (work) force in the future for Thailand. Finally, in previous assessment rounds, assessors were tasked to entail seven amicable assessment principles including attractiveness, respectfulness, praiseworthiness, persuasiveness, tolerance, lucidity, and dignity (Pornrungroj, 2011).

Table 2. Descriptive statistics of the observed variables

\begin{tabular}{|l|c|c|c|c|c|}
\hline \multicolumn{1}{|c|}{ Observable Variables } & Item & $\overline{\mathrm{x}}$ & S.D. & Skewness & Kurtosis \\
\hline Knowledge & $\mathbf{K}$ & & & & \\
\hline Early childhood education knowledge & KA & 4.31 & 0.56 & -5.57 & 1.60 \\
\hline Educational institution context knowledge & KB & 4.51 & 0.47 & -7.59 & 2.01 \\
\hline Educational quality assurance knowledge & KC & 4.27 & 0.43 & -3.82 & 0.45 \\
\hline Skills & S & & & & \\
\hline Planning skills & SA & 4.75 & 0.60 & -3.60 & 2.40 \\
\hline Data collection skills & SB & 4.79 & 0.563 & -5.15 & 3.14 \\
\hline Assessment Summary & SC & 4.86 & 0.39 & -1.19 & 0.13 \\
\hline Giving feedback skills & SD & 4.07 & 0.29 & -0.08 & 1.58 \\
\hline Report writing skills & SE & 4.04 & 0.26 & 3.06 & 4.10 \\
\hline Teamwork skills & SF & 4.27 & 0.43 & -6.96 & 0.34 \\
\hline Continuous self-improvement learning skills & SG & 4.20 & 0.57 & -1.59 & 2.29 \\
\hline Information technology (IT) skills & SH & 4.25 & 0.58 & -2.59 & 2.63 \\
\hline Aspects & $\mathbf{A}$ & & & & \\
\hline
\end{tabular}




\begin{tabular}{|l|c|c|c|c|c|}
\hline \multicolumn{1}{|c|}{ Observable Variables } & Item & $\overline{\mathbf{x}}$ & S.D. & Skewness & Kurtosis \\
\hline True friends & AA & 4.77 & 0.25 & -2.22 & 3.36 \\
\hline Good attitude towards quality assurance (QA) & AB & 4.36 & 0.61 & -7.71 & 1.46 \\
\hline Justice is impartial. & AC & 4.54 & 0.54 & 0.74 & 0.16 \\
\hline Punctuality & AD & 4.13 & 0.67 & -1.80 & 2.16 \\
\hline Integrity & AE & 4.04 & 0.62 & 0.56 & -0.17 \\
\hline Problem-solving ability & AF & 4.13 & 0.70 & -2.86 & -2.39 \\
\hline
\end{tabular}

S.D. = Standard Deviation

\section{Pearson's Product Moment Correlation Coefficient Assessment}

Pearson's correlation was further used to investigate the relationships of the 17 variables and the associated 136 observed variable pairs. From the analysis, Table 3 reveals that all the relationships were positive, with all variables having a significance of $p=0.01$. Furthermore, Hinkle et al. (2003) has suggested that correlation strengths be accessed as negligible from $.00-.30$, low from $.30-.50$, moderate from $.50-.70$, high from $.70-.90$, and very high from $.90-1.00$. Therefore, from the details in Table 4 , the relationship between SB and SA was determined to the highest (.81), while the relationship between $\mathrm{AB}$ and $\mathrm{KB}$ was judged to be the weakest $(0.20)$.

Table 3. Correlation matrix of observable variables for external assessor competency in early childhood education

\begin{tabular}{|c|c|c|c|c|c|c|c|c|c|c|c|c|c|c|c|c|c|}
\hline \multirow[b]{2}{*}{ Vbs. } & \multicolumn{17}{|c|}{ Coefficient Correlations } \\
\hline & $\begin{array}{l}\mathrm{K} \\
\mathrm{A}\end{array}$ & KB & $\mathrm{KC}$ & SA & SB & SC & SD & $\overline{S E}$ & $\mathrm{SF}$ & $\overline{S G}$ & $\begin{array}{l}\mathrm{S} \\
\mathrm{H}\end{array}$ & $\begin{array}{l}\text { A } \\
\text { A }\end{array}$ & $\mathrm{AB}$ & $\begin{array}{l}\text { A } \\
\text { C }\end{array}$ & $\begin{array}{l}\text { A } \\
\text { D }\end{array}$ & $\begin{array}{l}\mathrm{A} \\
\mathrm{E}\end{array}$ & $\begin{array}{l}\text { A } \\
F\end{array}$ \\
\hline KA & 1 & & & & & & & & & & & & & & & & \\
\hline KB & $\begin{array}{l}.5 \\
6\end{array}$ & 1 & & & & & & & & & & & & & & & \\
\hline $\mathrm{KC}$ & $\begin{array}{l}.3 \\
6\end{array}$ & .32 & 1 & & & & & & & & & & & & & & \\
\hline SA & $\begin{array}{l}.4 \\
3\end{array}$ & .56 & .45 & 1 & & & & & & & & & & & & & \\
\hline SB & $\begin{array}{l}.5 \\
5\end{array}$ & .27 & .25 & 81 & 1 & & & & & & & & & & & & \\
\hline SC & $\begin{array}{l}.5 \\
8\end{array}$ & .28 & .48 & .74 & .53 & 1 & & & & & & & & & & & \\
\hline SD & $\begin{array}{l}3 \\
2\end{array}$ & .22 & .36 & .40 & .55 & 44 & 1 & & & & & & & & & & \\
\hline SE & $\begin{array}{l}.5 \\
4\end{array}$ & .56 & .41 & .40 & .51 & .44 & .52 & 1 & & & & & & & & & \\
\hline SF & $\begin{array}{l}.4 \\
2\end{array}$ & .27 & .30 & 45 & .53 & .51 & .30 & .57 & 1 & & & & & & & & \\
\hline SG & $\begin{array}{l}.5 \\
1\end{array}$ & .51 & .40 & .57 & .55 & .60 & .54 & .50 & 42 & 1 & & & & & & & \\
\hline SH & $\begin{array}{l}.3 \\
6 \\
\end{array}$ & .55 & .46 & .54 & .52 & .39 & .25 & .50 & 34 & $\begin{array}{r}.2 \\
9 \\
\end{array}$ & 1 & & & & & & \\
\hline $\mathrm{AB}$ & $\begin{array}{l}.5 \\
7\end{array}$ & .20 & .31 & .53 & .50 & .51 & .26 & .22 & 45 & $\begin{array}{l}4 \\
2\end{array}$ & $\begin{array}{l}.4 \\
9 \\
\end{array}$ & $\begin{array}{l}.4 \\
4\end{array}$ & 1 & & & & \\
\hline AC & $\begin{array}{l}.5 \\
7\end{array}$ & .28 & .46 & .58 & .55 & .52 & .57 & .54 & 31 & $\begin{array}{l}4 \\
1\end{array}$ & $\begin{array}{l}.4 \\
1\end{array}$ & $\begin{array}{l}.4 \\
7\end{array}$ & .45 & 1 & & & \\
\hline $\mathrm{AD}$ & $\begin{array}{l}.2 \\
5\end{array}$ & .52 & .49 & .44 & .56 & .53 & .52 & .52 & 42 & $\begin{array}{l}4 \\
5\end{array}$ & $\begin{array}{l}.4 \\
9\end{array}$ & $\begin{array}{l}.4 \\
4\end{array}$ & .41 & $\begin{array}{l}.4 \\
0\end{array}$ & 1 & & \\
\hline $\mathrm{AE}$ & $\begin{array}{l}.3 \\
3\end{array}$ & .46 & .33 & .42 & .52 & .57 & .22 & .52 & 45 & $\begin{array}{l}.4 \\
4\end{array}$ & .4 & $\begin{array}{l}.4 \\
7\end{array}$ & .26 & $\begin{array}{l}.2 \\
8\end{array}$ & $\begin{array}{l}.4 \\
6\end{array}$ & 1 & \\
\hline
\end{tabular}




\begin{tabular}{|c|c|c|c|c|c|c|c|c|c|c|c|c|c|c|c|c|c|}
\hline $\mathrm{AF}$ & .3 & .53 & .32 & .40 & .41 & .50 & .30 & .46 & .33 & .4 & .4 & .4 & .30 & .3 & .2 & .5 & 1 \\
& 0 & & & & & & & & & 0 & 7 & 2 & & 4 & 5 & 3 & \\
\hline
\end{tabular}

Vbs. = Observed variables, all coefficient correlations were at the $\mathrm{p}=0.01$ significance level

\section{Measures of Sampling Adequacy}

To further determine the suitability for testing the model for factor analysis both the Kaiser-Meyer-Olkin (KMO) measure of sampling adequacy test and Bartlett's test of sphericity were used. Results revealed that the KMO's values were found to be 0.74 with a significance level at $p=0.01$. In KMO testing, values closer to 1 are considered best with a value of 0.6 used as a minimum.

Bartlett's test of sphericity was also used to test the hypothesis correlation matrix is an identity matrix. As the value was $\mathrm{p}<0.05$, this indicated that a CFA was appropriate and useful with the data. Furthermore, according to Kline (2011), a t-value should be $>1.96$ with a $p<0.05$.

Furthermore, Table 4 details the results from the $2^{\text {nd }}$ Order CFA. The $b_{s c}$ (standardized factor loading), the S.E. (standard error), t-value, and $\mathrm{R}^{2}$ validity are detailed.

Table 4. Statistical value results from the 2 nd order confirmatory factor analysis of the variables for early childhood QA education assessor competency

\begin{tabular}{|c|c|c|c|c|}
\hline \multirow{2}{*}{$\begin{array}{l}\text { Observed } \\
\text { variables }\end{array}$} & \multicolumn{4}{|c|}{$\begin{array}{l}\text { Factors affecting variables of EA Competence in early childhood } \\
\text { education }\end{array}$} \\
\hline & $b_{s c}$ & S.E. & t-value & Validity $\left(\mathrm{R}^{2}\right)$ \\
\hline Knowledge (K) & $0.81^{* *}$ & $<->$ & <--> & 0.73 \\
\hline KA & $0.87^{* *}$ & $<->$ & $<-->$ & 0.75 \\
\hline KB & $0.68^{* *}$ & 0.07 & 15.74 & 0.58 \\
\hline KC & $0.66^{* *}$ & 0.05 & 14.91 & 0.54 \\
\hline Skill (S) & $0.89^{* *}$ & $<->$ & $<->$ & 0.88 \\
\hline SA & $0.61^{* *}$ & $<->$ & $<-->$ & 0.48 \\
\hline SB & $0.84^{* *}$ & 0.08 & 18.11 & 0.82 \\
\hline SC & $0.73^{* *}$ & 0.05 & 17.41 & 0.61 \\
\hline SD & $0.76^{* \star}$ & 0.08 & 17.52 & 0.62 \\
\hline $\mathrm{SE}$ & $0.75^{* *}$ & 0.06 & 17.48 & 0.62 \\
\hline SF & $0.62^{* *}$ & 0.08 & 15.54 & 0.47 \\
\hline SG & $0.74^{* *}$ & 0.06 & 17.22 & 0.62 \\
\hline $\mathrm{SH}$ & $0.95^{* *}$ & 0.04 & 18.64 & 0.91 \\
\hline Aspects (A) & $0.79^{* *}$ & $<->$ & $<-->$ & 0.74 \\
\hline AA & $0.87^{\text {**}}$ & $<->$ & $<->$ & 0.87 \\
\hline $\mathrm{AB}$ & $0.61^{\star \star}$ & 0.047 & 14.48 & 0.50 \\
\hline $\mathrm{AC}$ & $0.85^{\text {** }}$ & 0.044 & 18.42 & 0.84 \\
\hline $\mathrm{AD}$ & $0.75^{\text {** }}$ & 0.059 & 17.48 & 0.62 \\
\hline $\mathrm{AE}$ & $0.64^{* *}$ & 0.082 & 15.62 & 0.51 \\
\hline $\mathrm{AF}$ & $0.63^{\star \star}$ & 0.049 & 16.24 & 0.49 \\
\hline
\end{tabular}

Chi-Square $=92.87, \mathrm{df}=80, \mathrm{p}=0.15, \chi^{2} / \mathrm{df}=1.16, \mathrm{RMR}=0.01, \mathrm{SRMR}=0.01, \mathrm{RMSEA}=0.01, \mathrm{GIF}=0.98$, $\mathrm{AGIF}=0.98$. Note: $* * \mathrm{p}<.01, \mathrm{~b}_{\mathrm{sc}}=$ standardized factor loading, <--> Refers to a mandatory parameter, $\mathrm{SE}=$ standard error values.

Figure 2 shows the final model for Thai external QA assessors which had a Chi-Square $=92.87, \mathrm{df}=$ $80, \mathrm{p}=0.15, \chi 2 / \mathrm{df}=1.16, \mathrm{RMR}=0.01, \mathrm{SRMR}=0.01, \mathrm{RMSEA}=0.01, \mathrm{GIF}=0.98, \mathrm{AGIF}=0.98$. Therefore, these results indicate that the external assessor competency model for early childhood education was structurally consistent with the empirical data. 


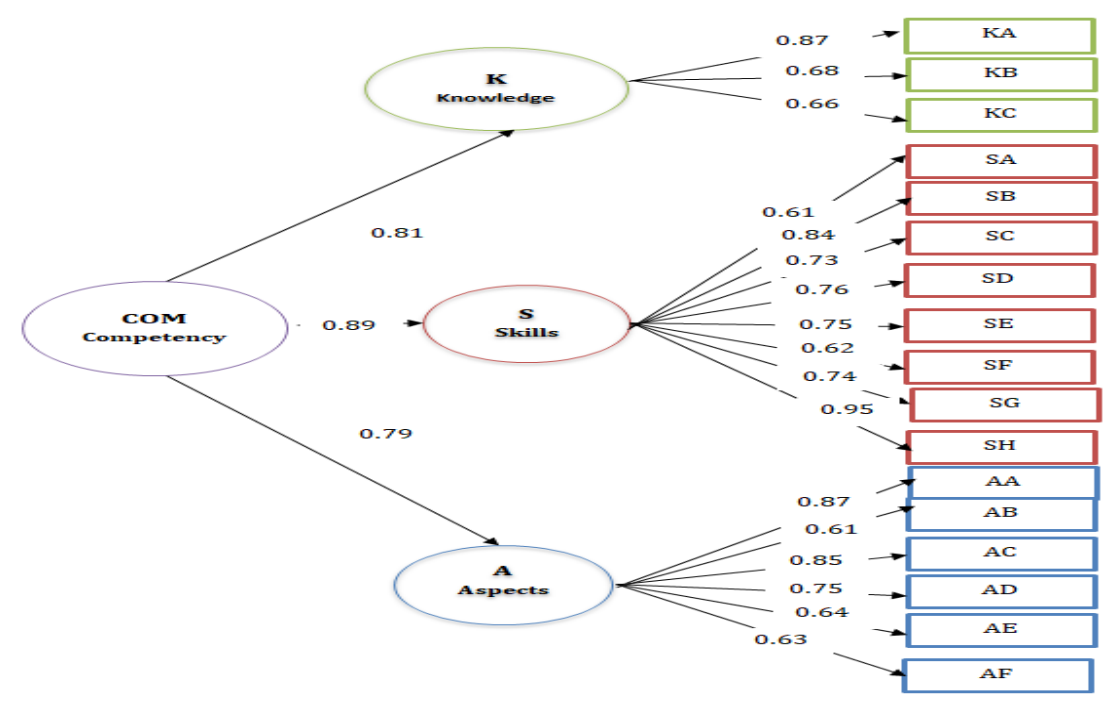

Figure 2. Structural validity of the early education external assessor competency indicator model corresponding to the empirical data.

\section{DISCUSSION AND CONCLUSIONS}

From the model's analysis, it was determined that assessors perceive their skills ( $\mathrm{S}$ ) and the skills of their colleagues as significantly important. Specifically, we note the strong agreement with information technology (SH) skills which had a $b_{s c}=0.95$. This is consistent with other studies, including Hungary (Arikan et al., 2017), a previous Thailand education assessor study (Suchiva et al., 2018), and in the U.S.A (Gohl et al., 2009), with D'Amico (2001) stating that the digital divide, inappropriate instructional use, and poor teacher preparation and training are major obstacles faced by US schools. Arikan et al. (2017) also determined that teacher confidence can be boosted with the introduction and adoption of learning technologies.

This was followed by two variables for both knowledge $(\mathrm{K})$ and aspects $(\mathrm{A})$. These were KA (early childhood education knowledge) and AA (true friends), with both having $\mathrm{b}_{\mathrm{sc}}$ values $=0.87$. Although KA is easy to understand, the concept of true friends might be strange to someone outside ONESQA's environment. However, as mentioned previously, true friends have evolved into the term Ambassadors of Quality beginning with the $3^{\text {rd }}$ five-year assessment cycle (ONESQA, 2015). Under these concepts, we find English words and phrases like 'amicable,' 'school doctor' and 'amicability assessors' as key elements in being a true friend or ambassador. Furthermore, ONESQA's director delivered a speech in which he referred to their policy of 'Ten Thousand Friends' (Pornrungroj, 2013), in which the organization feels the responsibility for educational quality comes from compliance with established standards while offering recommendations to schools and parent organizations on their ideas concerning improvements and development.

This is consistent with research from Wachirasakmongkol et al. (2014) concerning the 3rd Round (2011-2015) of assessors and feedback from their assigned schools. Once again, an external assessor's (EA) amicable approach proved far more satisfactory to each educational level group than EAs used in Round 1 and Round 2. It was additionally stated from the internal workshops and surveys that the basic education level EA group required EAs who were experienced in the education field itself and not hired from another profession.

Another aspect (A) viewed in high importance was the concept that justice is impartial (AC) with a $b_{s c}$ value $=0.85$. This is consistent with Yang (2013) which stated that justice and fairness are two key components needed for evaluation ethics, with professionalism the most essential aspect in education ethics.

Close behind AC was SB's data collection skills which had a $\mathrm{b}_{\mathrm{sc}}$ value $=0.84$. This appears to be closely related to information technology ( $\mathrm{SH}$ ) skills and has been identified as a factor for concern in other studies (UNESCO, 2019; Vista et al., 2018). Additionally, in Thailand, the preparation of data from each ONESQA assessment has become a topic of concern, with one study indicating that teachers spend nine of every 200 school days each year preparing for ONESQA's EA visit. Therefore, an EA's efficiency in data collection becomes a concern at many levels.

The next group ranked in importance were focused on each assessor's recommendation skills (SD) with a bsc value $=0.76$, report writing skills $(\mathrm{SE})\left(\mathrm{b}_{\mathrm{sc}}=0.75\right)$, continuous self-improvement learning skills 
$(\mathrm{SG})\left(\mathrm{b}_{\mathrm{sc}}=0.74\right)$, and assessment summary skills $(\mathrm{SC})\left(\mathrm{b}_{\mathrm{sc}}=0.73\right)$. Also, punctuality (AD) was judged to be of great importance $\left(b_{s c}=0.75\right)$.

Support for these ideas can be found in European documents concerning the requirements for pharmaceutical industry quality assessors (QA), which states that QAs need to have the ability to think independently with minimum supervision, and take responsibility for their work (Expert Group of Pharmaceutical Quality Assessors, 2011). Also, Tantimedh et al. (2013) added that different contexts require different skills and knowledge, with the need for continual refinement to enhance performance.

Finally, the group of items judged to be of the least importance to the EAs surveyed included their own educational institution context knowledge $(\mathrm{KB})$ which has a $\mathrm{b}_{\text {sc }}$ value $=0.68$. This was closely followed by their educational quality assurance knowledge $(\mathrm{KC})$ with a $\mathrm{b}_{\mathrm{sc}}$ value $=0.66$. These were followed by an EA's integrity (AE) ( $\left.b_{s c}=0.64\right)$, their problem solving ability (AF) ( $\left.b_{s c}=0.63\right)$, teamwork skills $(\mathrm{SF})\left(\mathrm{b}_{\mathrm{sc}}=0.62\right)$, planning skills $(\mathrm{SA})\left(\mathrm{b}_{\mathrm{sc}}=0.61\right)$, and a good attitude towards quality assurance $(\mathrm{AB})\left(\mathrm{b}_{\mathrm{sc}}=0.61\right)$, respectively.

One interesting note was raised from the results concerning the very low score of AE (integrity). Even though ONESQA's literature, speeches, and presentations are filled with words and images concerning an EA's integrity and ethics, the EAs surveyed for this study ranked the issues of integrity as an issue of low importance $\left(b_{s c}=0.64\right)$. It seems to us that someone along the way is not getting the message on the importance that ONESQA's management and numerous other studies place on an EA's integrity (Tantimedh \& Juntarasurin, 2013). This is a possible component for future research and analysis.

Additionally, outside research from Reeves (2007) has highlighted the importance of providing real-time feedback and immediate responses (AF). This allows better-informed parents as well as all levels throughout the educational process. This is also consistent with Tangwarasittichai et al. (2021) who observed that the process of educational institution quality control, quality inspection, and quality assessment is essential in educational quality development.

Concerning the low score for teamwork skills $\left(b_{s c}=0.62\right)$, this seems in sync with other global studies that places high emphasis on an EA's ability to think and act independently with little supervision.

Finally, the coefficient of reliability of all observable variables measured from $\mathrm{R}^{2}$ indicated that the covariance of the external assessor competency model for early childhood education was moderate to high, with an $\mathrm{R}^{2}$ between .47 and .91 (Table 4).

\section{REFERENCES}

Arbuckle, J. L. (2016). IBM ${ }^{\circledR}$ SPSS $®$ Amos $^{\mathrm{TM}} 24$ User's Guide. Amos Development Corporation. https://tinyurl.com/y6o4hphb

Arıkan, A., Fernie, D. E., \& Kantor, R. (2017). Supporting the professional development of early childhood teachers in head start: A case of acquiring technology proficiency. Elementary Education Online, 16(4), 1829 - 1849. https://doi.org/10.17051/ilkonline.2017.342996

Bollen, K. A., (1989). Structural equations with latent variables. Wiley.

Chantana, M., Yongsorn, C., \& Wongyunoi, S. (2019). Development of a competency framework for performance appraisal of higher education external assessors at the Office for National Education Standards and Quality Assessment (Public Organization). Sripatum Review of Humanities and Social Sciences, 19(1), 32 - 48. https://tinyurl.com/y63ud3zv

Curran, P. S., West, S. G., \& Finch, J. F. (1996). The robustness of test statistics to nonmorality and specification error in confirmatory factor analysis. Psychological Methods, 1(1), 16 - 29. https://tinyurl.com/yyyl36nh

D'Amico, J. J. (2001). Technology in America's schools: An overview of status and issues, ERS Spectrum, 19(1), 4 - 8. https://eric.ed.gov/?id=EJ621337

Diamantopoulos, A., \& Siguaw, J. A., (2000). Introduction to LISREL: A guide for the uninitiated. SAGE Publications, Inc,.

Dumrongkiat, M. (2017, June 9). Onesqa to cut teacher burden. Bangkok Post. https://tinyurl.com/y588hoph

European Commission. (2019). Montenegro - Quality assurance in early childhood and school education. https://tinyurl.com/y3d8sqfb

European Commission. (2019). Turkey - Quality Assurance. https://tinyurl.com/y4v9l4cn

European Commission. (2020). Hungary - Quality assurance in early childhood and school education. https://tinyurl.com/y2h5hloz

Expert Group of Pharmaceutical Quality Assessors. (2011). Competence requirements and training needs for Quality Assessors. https://tinyurl.com/y21r19g8 
Fan, X., \& Sivo, S. (2005). Sensitivity of fit indexes to misspecified structural or measurement model components: Rationale of two-index strategy revisited. Structural Equation Modeling, 12(3), 343 - 367. https://doi.org/10.1207/s15328007sem1203_1

George, D., \& Mallery, P. (2010). SPSS for Windows step by step: A simple guide and reference 17.0 update.

Pearson.

Gohl, E. M., Gohl, D., \& Wolf, M. A. (2009). Assessments and technology: A powerful combination for improving teaching and learning. In L. M. Pinkus (Ed.), Meaningful measurement: The role of assessments in improving high school education in the twenty-first century (pp. 183 - 197). Alliance for Excellent Education.

Gol-Guven, M. (2020). Ensuring quality in early childhood education and care: the case of Turkey. In K. Rentzou \& R. Slutsky (Eds.), Early Childhood Education and Care Quality in Europe and the USA (pp. 67 - 80). Routledge/ https://doi.org/10.4324/9780429283185-6 Actions

Hair. J. F., Black, W. C., Babin, B. J., \& Anderson, R. E. (2010). Multivariate Data Analysis (7th ed.). Person Education, Inc.

Hinkle, D. E., Wiersma, W., \& Jurs, S. G. (2003). Applied Statistics for the Behavioral Sciences. Houghton Mifflin.

Hussain A., \& Juma, A. (2006). Defining quality in early childhood settings: Experiences from the field. Aga Khan University Press. https://core.ac.uk/download/pdf/47255887.pdf

Kanyacome, S., Loipha, S. \& Numprasertchai, S. (2012). Needs of collaborative digital library for secondary school students in Thailand. In H. H. Chen \& G. Chowdhury (Eds.), The Outreach of Digital Libraries: A Globalized Resource Network. Lecture Notes in Computer Science, vol 7634. Springer.

https://doi.org/10.1007/978-3-642-34752-8_17

Kim, N. (2015). Tests based on skewness and kurtosis for multivariate normality. Communications for Statistical Applications and Methods, 22(4), 361 - 375.

http://dx.doi.org/10.5351/CSAM.2015.22.4.361

Kline, R. B. (2011). Principles and practice of structural equation modeling. Guilford.

NRC. (2001). Knowing What Students Know: The Science and Design of Educational Assessment; (2001). Committee on the Foundations of Assessment. National Research Council. https://tinyurl.com/y5gke2mp

OECD. (2017). Starting strong 2017: Key OECD indicators on early childhood education and care. OECD Publishing. https://dx.doi.org/10.1787/9789264276116-en

Office of the Higher Education Commission. (2014). Manual for The Internal Quality Assurance for Higher Education Institutions: Office of the Higher Education Commission (OHEC). https://tinyurl.com/y2oec43d

ONESQA. (2015). Quality assurance in Thailand. Office for National Education Standards and Quality Assessment. https://tinyurl.com/y5ewrqxw

ONESQA says its evaluation takes 5 hours, not 9 days. (2015, January 29). The Nation. https://tinyurl.com/y46jpgld

ONESQA. (2017). About ONESQA. http://www.onesqa.or.th/en/profile/973/

Pimdee, P. (2020). Antecedents of Thai student teacher sustainable consumption behavior. Heliyon, 6(8), e04676. https://doi.org/10.1016/j.heliyon.2020.e04676

Pitiyanuwat, S. (2007). School assessment in Thailand: roles and achievement of ONESQA. Educational Research for Policy and Practice, 6(3), 261 - 279. https://doi.org/10.1007/s10671-007-9023-0

Pornrungroj, C. (2011). Ambassadors of Quality, True friends who provide inspiration for educational institutions. Matichon Daily Newspaper. https://tinyurl.com/y6mnv3h2

Pornrungroj, C. (2013). Quality-student quality-teacher. Proceedings ICQA 2013 (pp. 13 - 22). https://tinyurl.com/y37uzu3d

Pornrungroj, C. (2015). Innovation on external quality assessment in Thailand. In Advanced research \& innovation in quality assurance (pp. 7 -16). ONESQA. https://tinyurl.com/y4tzq27z

Reeves, D. (2007). Ahead of the curve: The power of assessment to transform teaching and learning.

Solution Tree Press.

Ross, K. N. (2005). Module 3 - Sample design for educational survey research. In K. N. Ross (Ed.) Quantitative research methods in educational planning. IIEP-UNESCO. https://tinyurl.com/y4usvezb

Schumacker, R. E., \& Lomax, R. G. (2010). A beginner's guide to structural equation modeling. Routledge. 
Suchiva, S., Na-Songkhl, J., \& Panjamawat, T. (2018). Research to develop models and methods for developing external evaluators competencies. Journal of Research Methodology, 31(3), 257 279.

Tangwarasittichai, K., Leekitchwatana, P., \& Pimdee. P. (2021). Thai early childhood education external assessor competency indicator development. PalArch's Journal of Archaeology of Egypt / Egyptology, 18(3), 120 - 132. https://tinyurl.com/y4rm6t75

Tantimedh, A., Juntarasurin, P., Jongsawat, N., \& Premchaiswadi, W. (2013). Competency-based teaching and learning as a key to the Asean Economic Community success. Proceedings ICQA 2013 (pp. 79 87). https://tinyurl.com/y37uzu3d

Tantimedh, A., \& Juntarasurin, P. (2013). Competency-based Teaching and Learning as a Key to the Asean Economic Community Success. Proceedings ICQA 2013 (pp. 79 - 86). https://tinyurl.com/y37uzu3d

Turner, R. C., \& Carlson, L. (2003). Indexes of item-objective congruence for multidimensional items. International Journal of Testing, 3(2), 163 - 171. https://doi.org/10.1207/s15327574ijt0302_5

UNESCO.(2019). Brief 5 - Using data to improve the quality of education. https://tinyurl.com/y5pmx64a

Vista, A., Kim, H., \& Care, E. (2018, October 18). Use of data from 21st century skills assessments: Issues and key principles. https://tinyurl.com/y9bxgbnl

Wachirasakmongkol, B., Sengsri, S., \& Sirilak, S. (2014). The 3rd Round of operation pursuance of the external assessors: Case study of Naresuan University of Office for National Education Standards and Quality Assessment Network Center's responsible area. INTED2014 Proceedings. https://tinyurl.com/y6yqduee

Yang, F. (2013). Evaluation ethics. Proceedings ICQA 2013 (pp. 100 - 101). https://tinyurl.com/y675xsga 